\title{
Couple Relationships In Persons With Schizophrenia: Intimacy, Passion, And Commitment
}

Hadas Doron, Tel Hai Academic College, Israel

Adi Sharabi-Nov, Tel Hai Academic College, Israel

Mira Trablus, Tel Hai Academic College, Israel

Vivian Amory, Tel Hai Academic College, Israel

Yiftah Benbenishty, Tel Hai Academic College, Israel

Yehonatan Skuza, Tel Hai Academic College, Israel

Fares Issa, Tel Hai Academic College, Israel

\begin{abstract}
Couple relationships are a normative, yet crucial, aspect of human existence. They are a need shared by all mankind and thus serve as a powerful rehabilitative and beneficial tool among populations with special needs, including persons with mental illnesses. In the present study, 30 partners with chronic schizophrenia were compared to 20 normative partners regarding three aspects of couple relations - intimacy, commitment, and passion. Additionally, participants were asked to rate these three aspects in both their actual relationship and an ideal relationship. The schizophrenia cohort rated its actual relationships as lower in intimacy, commitment, and passion compared to the normative cohort. Also, disparities between perceptions of the aspects in both actual and ideal relationships were greater for the cohort with schizophrenia. Implications for practitioners are discussed with regard to their work in the couplehood field with persons with serious mental illnesses as well as in consciousness work among the normative community.
\end{abstract}

Keywords: Schizophrenia; Couple Relations Intimacy; Passion; Commitment

\section{INTRODUCTION}

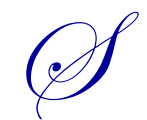

chizophrenia is a mental disorder characterized by a breakdown of thought processes and by poor emotional responsiveness. The DSM-IV-TR describes schizophrenia in terms of positive and negative symptoms - positive symptoms include delusions, disordered thoughts and speech, grossly disorganized or catatonic behavior, and hallucinations; negative symptoms listed are affective flattening, alogia, and volition. For a significant period of time after the onset of schizophrenia, one or more major areas of functioning, such as work, interpersonal relations, or self-care, are markedly below pre-illness levels.

This paper examines the couple relations of partners with chronic schizophrenia and attempts to identify unique elements characterizing their partnerships in comparison to those of the normative population. The research uses Sternberg's Triangular Love Scale, which measures three aspects of couplehood - commitment, intimacy, and passion. Commitment requires the allocation of resources for giving, planning for the short and long term, thoughtfulness, and patience. Intimacy commonly refers to an interpersonal experience entailing closeness and deep knowledge of the other. It also involves a component of self-exposure, a process through which a person shares significant feelings and personal information with another. The third aspect is passion which refers to intimate attraction (Mccabe, 1997).

During recent decades, there has been a shift in perceptions of appropriate rehabilitation for mentally ill patients and a wide range of community-based programs have been established. Their basic tenets are the development of self-efficacy, functional independence, and self-realization. The present research stems from the 
authors' professional experience and is based on the need of the authors to deal with two main issues. The first is the longing for couplehood expressed by patients they have encountered. The authors appreciate that an important milestone in the therapeutic process has been reached when persons with schizophrenia express the desire to be significant to another person. To experience commitment, intimacy, and passion, in accordance with the natural right of any human being, is a central need, as the authors see it, on the route to recovery. Second, although many studies have been conducted in the fields of marriage and couplehood, there is scarcely any reference in the literature to couplehood among persons with mental illness, in general, especially those with schizophrenia. The authors found themselves lacking basic professional knowledge in this field and, consequently, unable to properly articulate constraints, limitations, and goals when planning an intervention.

\section{Personal Relations Among Persons With Schizophrenia}

Deficiencies in interpersonal functioning are a prominent factor in schizophrenia. Individuals with schizophrenia experience changes in their emotional lives, become indifferent to their surroundings, have difficulties in generating social contact, and gradually diminish contact with others and withdraw into an inner world. They therefore suffer from declined functioning in both the social and occupational spheres (Elizur, Tiano, \& Munitz, 2002).

Arazi-Hirshberger (2001) claims that the lives and social abilities of persons with schizophrenia are usually limited, so they report solitude and that their relations with family members are limited solely to relying upon them. This may cast a shadow on the recovery process because of the inferior quality of intra-family relations and the typically inferior modes of communication of persons with schizophrenia (Erickson, Beiser, Iacono, Fleming, \& Lin, 1989). Beyond familial relationships, Elizur and her colleagues (2002) contend that the contact that persons with schizophrenia have with their surrounding worlds may be restricted to meetings with the professional staff treating them. They also contend that professionals see social solitude as one of the main obstacles to rehabilitation.

\section{Couple Relations Among Persons With Schizophrenia}

Couple relationships are, in general, based on the fundamental need to belong and on the desire and impulse to create meaningful interpersonal contact (Baumeister \& Leary, 1995). The aim of couplehood is to produce intimacy, closeness, and deep relations with one's partner. One question to be asked is how to characterize couple relationships among persons with schizophrenia.

Weiss-Golan (2005) states that in contrast to the normative population, which is exposed to a variety of workplaces, recreation venues, and possibilities for initiating social contacts, persons with schizophrenia are more restricted in their choices and may consequently be limited to choosing a partner from within their own rehabilitation framework who is in a situation similar to their own. This may result in the absence of a more suitable partner in a relationship with someone who does not suit their needs.

Loranger's (1984) study on this topic found that persons with schizophrenia marry less - fewer than $25 \%$ of men and 50-70\% of women married. According to Goldstein, Tsuang, and Faraone (1989), apart from marriage, women with schizophrenia are more involved in heterosexual relationships than men with schizophrenia. Snyder and Whisman (2003) attribute the difference to the relatively late onset of the disease among women as well as to differences in gender roles during the courting process. On the other hand, the marital relations of men with schizophrenia tend to be more successful than those of the women, probably related to the age of onset as well as to their partners' attitude towards the condition.

The few studies that enquired into the nature of such relationships and their effect on partners with schizophrenia revealed that, by-and-large, couplehood benefits them and may also improve their condition. Research shows that $35-40 \%$ of psychiatric patients return to cohabit with their partners and married patients have fewer recurring hospitalizations and are more successfully integrated into the community than bachelors and divorcees. This finding may be accounted for by the basic and universal need of people to feel loved and desirable by their surroundings - a need fulfilled by the couple relationship (Yechieli, 2004). Fisher (1991) carried out an in-depth examination of the relationships of three couples comprised of two partners with schizophrenia living in the 
community and found that their most significant perception was a sense of satisfaction and contentment from achieving couplehood. The partners perceived marriage as sign of normality and a status to be aspired to in order to integrate and be accepted in the community. Weiss-Golan (2005) found that most of her research participants with schizophrenia described their initial meeting with a partner as more rational than love-at-first-sight or an immediate infatuation. She claims that the need to dispel their solitude is so important that many are willing to be practical and so resign themselves to being less selective in choosing partners.

Geiger, Friedman, Ordan, Lasry, and Ohn (2005) found that in light of the effects of new-generation psychiatric drugs in reducing the negative symptoms of schizophrenia, patients are able to enter into relationships in which they do not regress into an inner world, but improve their motivational deficit, sharpen their attention abilities, and increase self-awareness and the awareness required to identify their partner's emotional needs. As a result, they are capable of experiencing loving relationships.

In his previously mentioned study, Fisher found (1991) a deep sense of commitment between partners with schizophrenia. Contrary to the hypotheses that persons with schizophrenia experience difficulties in building normative relationships, the three couple relationships he studied were found to be typified by openness, acceptance, reciprocal disclosure, respect, and appreciation. He depicted partners as living "with one another" rather than "one next to the other"; they did not see the illness as a part of their partner's personality, but as a single, isolated, and temporary aspect of it.

Yechieli (2004) claims that the negative attitude of society towards psychiatric patients, a probable cause of social isolation, may strengthen intra-familial ties and lead to stronger cohesion between such partners. Another factor contributing to cohesion is acceptance of the illness and a shared effort to effectively cope with it. Snyder and Whisman (2003) add that a psychotic episode usually constitutes an intensely stressful situation and may make partners feel closer to each other. Some of the interviewees who participated in Weiss-Golan's (2005) research said they preferred coping with their illness together with another person who had experienced it themselves rather than with a normative person who was not able to understand or accept their illness.

Besides the positive findings reported above, however, Fisher's (1991) study reported findings that indicate some deviations within relationships between persons with schizophrenia that constitute overt expressions of the pathology. These were mainly manifested in a non-normative division of roles - role fulfillments that seemed to be imitations of life rather than life itself, high dependency between partners, regression from external social relations (seclusion), and defects in sexual functioning. Snyder and Whisman (2003) argue that the cognitive deficits identified with schizophrenia make having and maintaining couplehood more difficult, and indeed the rate of separation and divorce is high for such couples. They also state that difficulties in shared coping and in understanding a partner's emotional expressions are significant deficits affecting couple relations. Additionally, sometimes due to depressive states, participants reported lack of motivation to communicate and a will to withdraw which, in turn, may impair the couple experience (Weiss-Golan, 2005).

Regarding sexual relations, high rates of dysfunction were discovered in all aspects (passion, arousal, and orgasm) among both men and women with schizophrenia (Weiss-Golan, 2005; Fan, Henderson, Chiang, Briggs, Freudenreich, \& Evins, 2007). The study of sexual functioning among persons with schizophrenia was triggered by the appearance of psycho-tropic drugs and focuses mainly on the drugs' side effects. The most prevalent of these are erectile and ejaculation dysfunction, swelling of the testicles, impotency, lack of sperm, and pain during erection in men; disruptions in the menstrual cycle in women; and decreased sexual desire and enlargement of the mammary glands in both genders (Nestoros, Lehman \& Ban, 1981). Bhui, Puffet, and Starthdee (1997) examined the sexuality of persons with psychotic disturbances. They found that those suffering from persistent psychoses are negatively affected by their illness but try to maintain a healthy sexual identity.

Basing their research on Zubin and Spring's (1977) stress vulnerability model for understanding schizophrenia, Snyder and Whisman (2003) claim that against the backdrop of the patients' biological vulnerability, stressful events resulting from close relationships - or, alternatively, the lack of them - may constitute a significant factor in the development of the illness. They argue that understanding how relationships affect schizophrenia, whether positively or negatively, may assist in the process of rehabilitation and recovery. 


\section{RESEARCH HYPOTHESES}

A review of the literature reveals that scarcely any research has been conducted on persons with schizophrenia in couple relationships. The present research aims at illuminating these relationships in general, particularly in reference to commitment, passion, and intimacy. The authors' research hypotheses were:

1. Persons with schizophrenia and normative persons perceive the quality of their couple relationships differently regarding commitment, intimacy, and passion.

2. There is a greater disparity between perceptions of their actual relationships and an ideal relationship regarding commitment, intimacy, and passion among persons with schizophrenia than among normative persons.

\section{METHOD}

\section{Participants}

This study was carried out on a cross-sectional sample of persons with schizophrenia who live in the community and are in couple relationships. It was conducted in hostels and supportive communities in northern Israel. The research cohort included 30 participants with schizophrenia receiving drug therapy who had been hospitalized at least once in a psychiatric institution and a control cohort of 20 participants with no previous history of psychiatric illness. The total number of participants included 31 women $(62 \%)$ and 19 men, with an average age of $42.9(\mathrm{SD}=13.8)$ (see Table 1$)$. Each participated voluntarily and signed a consent form.

Table 1: Demographic Variables Of The Sample

\begin{tabular}{|c|c|c|c|c|}
\hline & \multicolumn{2}{|c|}{ Normative } & \multicolumn{2}{|c|}{ Schizophrenia } \\
\hline Variable & $\mathbf{N}$ & $\%$ & $\mathbf{N}$ & $\%$ \\
\hline \multicolumn{5}{|l|}{ Gender } \\
\hline Male & 2 & 10.0 & 17 & 56.7 \\
\hline Female & 18 & 90.0 & 13 & 43.3 \\
\hline \multicolumn{5}{|l|}{ Education } \\
\hline High school & 10 & 50.0 & 29 & 96.7 \\
\hline Post-secondary & 10 & 50.0 & 1 & 3.3 \\
\hline \multicolumn{5}{|l|}{ Country of Birth } \\
\hline Israel & 17 & 85.0 & 17 & 56.7 \\
\hline \multirow[t]{2}{*}{ Other } & 3 & 15.0 & 13 & 43.3 \\
\hline & $M$ & SD & $\mathrm{M}$ & SD \\
\hline Age & 34.1 & 7.8 & 48.7 & 14.0 \\
\hline Age of spouse & 35.6 & 8.7 & 46.3 & 13.4 \\
\hline Number of Children & 1.6 & 1.8 & 0.9 & 1.4 \\
\hline
\end{tabular}

The participants in the research cohort were all above 18 years of age, were officially recognized by the National Insurance Institute as suffering from schizophrenia, and had all undergone evaluation for eligibility for a rehabilitation basket from of the Israeli Ministry of Health. In addition, all lived in the community (hostels, private homes, protected accommodation, or supporting communities) and were in full or partial couple relationships. The functioning levels of the participants were varied, though the authors attempted to choose those with minimal postpsychotic disabilities and without severe negative symptoms of the disease so they would be able to participate in the interview both emotionally and cognitively with some understanding and depth. The total research sample (research and control groups) included 29 men and 31 women, with an average age of 43 years. All participants participated voluntarily and signed a consent form.

\section{Instruments}

Aspects of the participants' romantic/couple relationships were measured by means of the Sternberg Triangular Scale - a self-report questionnaire comprised of 36 statements. Participants rated the degree to which each statement described their feelings regarding a romantic relationship according to a six-point Likert scale 
ranging from 1 (not at all) to 6 (to a great extent). The Sternberg scale measures three aspects of couplehood: 1) twelve statements measure attitudes and feelings that reflect on intimacy in a relationship; for example, "I feel very emotionally close to my partner" $(\alpha=0.96) ; 2)$ eleven statements measure passion in the relationship, for example, "My partner is very important in my life" ( $\alpha=0.93)$; and 3) thirteen items measure commitment in the relationship, for example, "I feel a sense of responsibility toward my partner" $(\alpha=0.85)$ (Sternberg, 1997). The statements were presented in the questionnaire randomly and the three aspects of couplehood were calculated as the means of the respective statements. Nothing in the literature indicates the need to add the internal reliability of Sternberg's scale.

All of the participants in the study completed two distinct versions of the questionnaire. For the first, they were asked to rate the degree to which each statement describes their feelings regarding their actual partner (heretofore, their actual relationship) and for the second, they were first asked to imagine a relationship with an ideal partner and then asked to complete the questionnaire, rating to what degree each statement described their feelings toward their ideal partner as if they were in a relationship (heretofore, their ideal relationship). The reliability scores of this version were intimacy $\alpha=0.90$, passion $\alpha=0.87$, and commitment $\alpha=0.86$.

\section{Procedure}

Data collection from the research cohort was carried out through interviews and completion of questionnaires. The task of recruiting relevant participants was carried out by one of the authors of this study who works in the rehabilitation sector. Through her acquaintanceship with other professionals in the field appropriate candidates were identified and recruited.

The research was carried out in the sheltered residences of the interviewees. The questionnaires were filled out by the interviewer who explained each statement slowly, deliberately, and sensitively. Before filling out the questionnaires, all participants had given their consent in writing and orally, understanding that their privacy was of utmost importance. During the interviews, it was discerned that the participants wanted to contribute to the study; nevertheless, most expressed impatience and suspicion.

The control cohort comprised of 20 participants in couple relationships who had no history of schizophrenia or any other mental illness. Members of the control cohort completed the questionnaires themselves.

\section{Ethics}

Ethics in research encompasses principles, commitment, and behavior that must guide the researcher. Ethical behavior is integral to a research study and therefore must be examined at each stage of the study. The questionnaires were administered in a supportive and accepting atmosphere in order to foster a sense of empowerment and repose among the participants. Interviewees were confident of the researcher who helped them complete the questionnaire and were secure that their identities would remain a secret and their privacy would be maintained.

\section{RESULTS}

The objective of the research was to examine the quality of relationships among persons with mental illness in comparison to normative persons. The study focuses on aspects of couplehood; that is, on various aspects of relationships, as tested in the Sternberg Triangular Scale - commitment, intimacy, and passion - and on the differences in perceptions of these aspects in actual relationships and ideal relationships among the two cohorts.

Table 2 illustrates that the mean score of the schizophrenia cohort was significantly lower than the normative cohort in all aspects of couplehood with regard to both their actual relationships and ideal ones ( $<$ <.05). 
Table 2: Means, SDs, And Differences Between The Schizophrenia Cohort And

The Normative Cohort Regarding Aspects Of Couplehood In Actual Relationships And Ideal Relationships

\begin{tabular}{|c|c|c|c|c|c|c|}
\hline 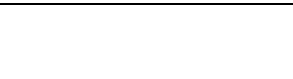 & \multicolumn{2}{|c|}{$\begin{array}{c}\text { Schizophrenia } \\
(\mathbf{n}=\mathbf{3 0})\end{array}$} & \multicolumn{2}{|c|}{$\begin{array}{c}\text { Normative } \\
(\mathbf{n}=\mathbf{2 0})\end{array}$} & \multirow[t]{2}{*}{$\mathbf{t}$} & \multirow[t]{2}{*}{$\mathbf{p}$} \\
\hline & $M$ & SD & $M$ & SD & & \\
\hline \multicolumn{7}{|l|}{ Actual relationship } \\
\hline Commitment & 4.4 & 1.0 & 5.5 & 0.6 & 4.922 & 0.000 \\
\hline Intimacy & 4.6 & 0.9 & 5.4 & 0.6 & 3.782 & 0.000 \\
\hline Passion & 4.3 & 1.1 & 5.2 & 0.7 & 3.445 & 0.001 \\
\hline \multicolumn{7}{|l|}{ Ideal relationship } \\
\hline Commitment & 4.9 & 1.0 & 5.9 & 1.2 & 4.113 & 0.001 \\
\hline Intimacy & 4.9 & 0.9 & 5.6 & 0.4 & 3.466 & 0.003 \\
\hline Passion & 5.2 & 1.0 & 5.6 & 0.4 & 1.774 & 0.044 \\
\hline
\end{tabular}

Since Table 2 shows that among both cohorts the mean of each of the three aspects of couplehood is higher for ideal relationships than for actual relationships, calculating the difference between the score for ideal relationships and actual relationships allowed the authors to study this phenomenon. Subsequently, they tested the mean differences between the scores of the schizophrenia cohort and the normative cohort for each of the three aspects of couplehood (Table 3).

Table 3: Differences Between Scores For Actual And Ideal Relationships In The Schizophrenic Cohort And The Normative Cohort

\begin{tabular}{lcc|cccc}
\hline & \multicolumn{2}{c|}{$\begin{array}{c}\text { Schizophrenia } \\
(\mathbf{n = 3 0 )}\end{array}$} & \multicolumn{2}{c}{$\begin{array}{c}\text { Normative } \\
(\mathbf{n = 2 0})\end{array}$} & t & p \\
\cline { 2 - 7 } Differences between scores for & $\boldsymbol{M}$ & SD & $\boldsymbol{M}$ & SD & & \\
ideal and actual relationships & 0.5 & 0.6 & 0.4 & 1.1 & 0.198 & 0.422 \\
\hline Commitment & 0.3 & 0.3 & 0.1 & 0.3 & 2.270 & 0.014 \\
Intimacy & 0.8 & 0.8 & 0.4 & 0.6 & 2.063 & 0.023 \\
Passion & & & & &
\end{tabular}

The mean differences in scores for perceptions of ideal relationships as opposed to actual relations for intimacy and passion were greater for the schizophrenic cohort than for the normative cohort ( $\mathrm{p}<.05)$. Although the same held true for the commitment scores ( 0.5 and 0.4 , respectively), the difference was not statistically significant (p>.05). Furthermore, no statistically significant differences were found between women and men in the means of the aspects tested in Sternberg's scale ( $p>.05)$ either among the total population of participants or each cohort separately.

\section{DISCUSSION}

The aim of the present study is to examine the experiences and perceptions of persons with schizophrenia who are in couple relationships. The authors' choice of this subject derived from their work with persons with mental illnesses, their exposure to the sincere desire of many of them to be part of a stable couple relationship, and their difficulty in achieving this goal.

Findings indicate that, in accordance with the authors' hypotheses, there are significant differences in how persons with schizophrenia perceive their couplehoods/partners as opposed to normative persons. Differences were found in all three aspects of relationships examined - commitment, intimacy, and passion. They also found significant differences between the groups in the mean perception of actual relationships and mean perception of ideal relationships in intimacy and passion, though not in commitment.

The discussion hereinafter will focus on the significant differences that were found in the research. In addition, the authors will present a number of suppositions that may shed light on the results and account for the implications of the illness on the participants' subjective perception of their couple relationships. 


\section{Commitment}

The authors found that the research cohort showed statistically significant lower grades of commitment than the control cohort, both for actual and ideal relationships. This finding conflicts with Fisher (1991) regarding the deep commitment he found to characterize the couplehood of persons with schizophrenia. Although Yechieli (2004) reported high rates of cohesion among such couples, the findings do not necessarily pose a contradiction since commitment, as opposed to cohesion, requires the investment of personal resources by the partners. Homan and Bau's exchange theory (in Poloma, 1979), which suggests that personal and interpersonal resources act within a remunerative system, can account for this finding. It is plausible that due to their illness, persons with schizophrenia are called upon to invest greater personal resources - time, thought, and feelings - internally in order to maintain their well-being, leaving relatively few resources free for external relationships, including with partners. Moreover, aversion to investing personal resources in couplehood may occur because of partners withdrawing into their internal world (Elitzur, Tiano, \& Munitz, 2002) or as a symptomatic expression of lack of interest and apathy (Cancro \& Lehmann, 1998; Nevid, Rathus, \& Greene, 2000; Tsuang \& Faraone, 1997).

\section{Intimacy}

The authors found that the research cohort showed statistically significant lower grades of intimacy than the control cohort for both actual and the ideal relationships. The same defects in interpersonal relations ascribed to persons with schizophrenia in the literature review - those related to cognitive and communicative deficits and to social withdrawal - may account for this finding. To some extent, the findings correspond with Arazi-Hirshberger's (2001) assertion that persons with schizophrenia are unable to experience enjoyment, preventing them from initiating social relations, as well as the claim of Geiger et al. (2005) that flatness and inadequacy of affect, lack of interest, and concentration deficits influence the social ability and skills of their participants.

\section{Passion}

The authors found that the research cohort showed statistically significant lower rates of passion than the control cohort for actual relationships. The rate for ideal relationships was also lower, but not statistically significant. This finding corresponds to the claim of Keefe et al. (1989) that "instrumental social regression" characterizes persons with schizophrenia. They claim that patients may experience a decline in autonomic arousal, which is related to higher levels of mental, perceptive, and emotional deficits as a result of withdrawal from social interactions. This may account for the authors' finding. In other words, it is plausible that persons with schizophrenia unconsciously decrease their level of passion in order to decrease their autonomic arousal. Fan et al. (2007) found a higher level of deficits in all aspects of sexual functioning (passion, arousal, and orgasm) among men and women with schizophrenia. Nestoros, Lehman and Ban (1981) related similar findings to the side effects of psychiatric drugs on patients with schizophrenia.

\section{Disparities Between Perceptions Of Actual And Ideal Relationships}

The last prominent finding, for which there is no evidence in the existing literature, shows that the difference in reported levels of intimacy and passion between actual and ideal relationships are higher and more significant in the research cohort than in the control cohort. The difference in reported levels of commitment is higher as well, although not statistically significant. Such a disparity between the actual and the ideal might indicate dissatisfaction, frustration, and disappointment in the actual relationship. It is therefore apparent that although Fisher's (1991) finding that persons with schizophrenia feel their couple relationships furnish them with a strong sense of satisfaction and happiness because they have achieved normality (which they interpret as reacceptance into society), the present research points to lack of satisfaction and is therefore worthy of further inquiry.

A wide disparity indicates a lack of realistic perceptions or, in other words, some distortion of either the actual or the ideal relationship and polarization between the two. This may be due to the effects of what Snyder and Whisman (2003) state are the symptoms of schizophrenia, including false self-perception and lack of full recognition of the disability, which shadow close relationships, or the cognitive deficits they identify with schizophrenia, which make having and maintaining relationships difficult. Eventually, persons with schizophrenia find it hard to reduce the disparity between their actual situation and the one they desire, leaving them frustrated and 
disappointed. Yet a different explanation may lie in Weiss-Golan's (2005) study in which most participants with schizophrenia reported that the circumscribed social circle to which they belong confines them to a limited selection of potential partners. They therefore make more rationalistic choices in partners, one entailing compromise. The authors' findings may throw light on how concessions of this kind lead to frustration and disappointment in the long run.

\section{PROPOSALS FOR FUTURE RESEARCH}

Due to the shortage of literature in the field, the restricted population, and difficulties in using existing measures with this population, the present research was conducted using a relatively small research sample (30 participants). In the future, similar research should be expanded and use adapted measuring tools validated to measure aspects of couple relationships of persons with schizophrenia and be administered to a larger sample to enable generalization. Additionally, since the present research sample includes only persons with schizophrenia, the authors recommend that future research examines populations diagnosed with other mental illnesses, such as mood disorders and severe anxiety disorders, and study the significance of couplehood among them.

It is also important to try and map intervening variables, such as the severity of the illness, gender, age, and social support, in order to design rehabilitative intervention programs that will offer ways for populations with serious mental disabilities, specifically persons with schizophrenia, to be involved in beneficial couple relationships.

\section{CONCLUSION}

The present research has great significance both for persons with serious mental disabilities and the practitioners who work with them. Today, in an era in which social and therapeutic policies regarding mental disabilities focus on reducing hospitalizations and increasing rehabilitative services within the community, it is clear that being in a couple relationship, as was found in former studies, is an important element contributing to improvement in self-image, self-confidence, and a sense of normality.

A couple relationship experienced as favorable by the partners helps them cope with their mental illness and constitutes a supportive factor that contributes to a better recovery. Therefore, rehabilitation should include programs that concentrate on promoting and encouraging couplehood, working to increase relational abilities and skills. This should be carried out in both group and individual practice and within a wide range of interventional methods, including therapy, supervision, and presentations, workshops, art therapy, and other alternative therapeutic methods.

For rehabilitation practitioners, this research may contribute to the understanding of yet another aspect of in-community rehabilitation, one that has yet to be addressed. Understanding the nature and characteristics of couplehood in persons with schizophrenia, and understanding the significance they placed on it, has the potential to assist practitioners and professionals in directing, supporting, and encouraging couplehood in their work.

While engaging in the research, the authors encountered difficulties in reaching the population and in conducting the interviews, which forced them to study only a limited number of participants and thus prevented them from conducting a distinctive differentiation between couples in which only one partner has schizophrenia and those in which both partners have it. Finally, a major difficulty they encountered was caused by the general exclusion of the research population from empirical study; especially noticeable was the scarcity of literature relating to couple relationships of persons with schizophrenia. In light of accelerated research in the field of rehabilitation of persons with serious mental disabilities, this was a surprise and somewhat limited the authors' own research. In their opinion, the reason may lie in a conflict emanating from social taboo. While rehabilitation professionals may indeed agree on the fundamental worth of couplehood, the issue nevertheless strums society's finest strings of anxiety. As patients move yet another step towards self-fulfillment, the most obvious outgrowth of couplehood may lead to a moral dilemma - such relationships may lead to offspring, themselves carrying a genetic disposition to the illness. This may be considered harmful to society and counter to the good of the community. The authors have encountered this moral dilemma during their work with persons with serious mental disabilities and regretfully fear it continues behind closed doors. 
In light of the above, practitioners and caregivers should work not only to promote and encourage the initiation and generation of such relationships among the population with serious mental disabilities, but also to inform and guide the public; that is, the normative community. Stress should be placed on such population's abilities and skills in engaging in couple relationships, as well as the feasibility and prevalence of such relationships. Couple relationships of persons with mental illness should be granted light and platform and be brought more to consciousness, reducing the perception that they are uncommon and odd.

\section{AUTHOR INFORMATION}

Dr. Hadas Doron is a Senior Lecturer in the Social Work Department of Tel Hai College, Israel. Dr. Doron's research interests include familial and marital relationships in abnormal circumstances and gender differences at different stages of life. Dr. Doron is a certified therapist and has a private clinic for family and couples therapy. Email: hadasdoron@012.net.il. (Corresponding author)

Adi Sharabi-Nov is a lecturer in the Social Work Department of Tel Hai College, Israel. Her interests include statistics, family relations, and medical research. E-mail: adishra@telhai.ac.il.

\section{REFERENCES}

1. American Psychiatric Association. (2000). Task Force on DSM-IV-TR. Pub. ISBN 9780890420256. p. 299.

2. Arazi-Hirshberger, N. (2001). Satisfaction from sexual activity among persons with schizophrenia and its relation to severity of disease and intimacy. Unpublished master's thesis, Bar-Ilan University, Israel. [Hebrew].

3. Baumeister, R. F. \& Leary, M. R. (1995). The need to belong: Desire for interpersonal attachment as a fundamental human motivation. Psychological Bulletin, 117(3), 497-529.

4. Bhui, K., Puffet, A., \& Strathdee, G. (1997). Sexual and relationship problems amongst patients with severe chronic psychoses. Social Psychiatry and Psychiatric Epidemiology, 32, 459-467.

5. Cancro, R. \& Lehmann, H. E. (1998). Schizophrenia: Clinical features. In H. I. Kaplan \& B. J. Sadock (eds.), Comprehensive text book of psychiatry (pp. 1169-1199). Baltimore, MD: Williams \& Wilknis.

6. $\quad$ Elitzur, A., Tiano, S., \& Munitz, H. (2001). Selected chapters in psychiatry, Tel-Aviv, Israel: Papyrus Press. [Hebrew].

7. Erickson, D. H., Beiser, M., Iacono, W. G., Fleming, J. A. E., \& Lin, T. (1989). The role of social relationships in the course of first-episode schizophrenia and affective psychosis. American Journal of Psychiatry, 146(11), 1456-1461.

8. Fan, X., Henderson, D. C., Chiang, E., Briggs, L. B. N., Freudenreich, O., \& Evins, A. E. (2007). Sexual functioning, psychopathology and quality of life in patients with schizophrenia. Schizophrenia Research, 94(1-3), 119-127.

9. Fisher, M. (1991). Marriage life of couples of chronic mentally disabled in the community. Unpublished master's thesis, Tel Aviv University, Israel. [Hebrew].

10. Geiger, B., Friedman, G., Ordan, H., Lasry, A., \& Ohn, T. (2005). Love among couples diagnosed with schizophrenia. International Journal of Psychosocial Rehabilitation, 10 (1), 105-122.

11. Goldstein, J. M., Tsuang, M. T., \& Faraone, S. V. (1989). Gender and schizophrenia: Implications for understanding the heterogeneity of the illness. Psychiatry Research, 28(3), 243-253.

12. Keefe, R. S. E., Siever, L. J., Mohs, R. C., Peterson, A. E., Mahon, T. R., Bergman, R. L., \& Davis, K. L. (1989). Eye tracking, schizophrenic symptoms, and schizotypal personality disorders. European Archives of Psychiatry and Clinical Neuroscience, 239(1), 39-42. doi: 10.1007/BF01739742.

13. Loranger, A. W. (1984). Sex differences at age of onset of schizophrenia. Archives of General Psychiatry, 41, 157- 161.

14. McCabe, M. P. (1997). Intimacy and quality of life among sexuality dysfunctional males and females. Journal of Sex and Marital Therapy, 23, 276-290.

15. Nestoros, J., Lehman, H., \& Ban, T. (1981). Sexual behavior of the male schizophrenic: The impact of illness and medications. Archives of Sexual Behavior, 10, 421-442.

16. Nevid, S. J., Rathus, S. A., \& Greene, B. (2000). Abnormal psychology in a changing world. Upper Saddle 
River, N J: Prentice Hall.

17. Poloma, M. M. (1979). Contemporary sociological theory. New York: Macmillan.

18. Snyder. D. \& Whisman, M. (2003). Treating difficult couples. New York, NY: Guilford Press.

19. Tsuang, T. M. \& Faraone, S. (1997). Schizophrenia: The facts. New York, NY: Oxford University Press.

20. Weiss-Golan, E. (2005). Experience and meaning of couple relationship for couples in which both partners have schizophrenia. Unpublished master's thesis, University of Haifa, Israel. [Hebrew].

21. Yechieli, H. (2004). A group psycho-educational intervention model for partners coping with a psychiatric disability. Hevra Ve'Revacha, 24(1). 79-100. [Hebrew].

22. Zubin, J. \& Spring, B. (1977). Vulnerability: A new view of schizophrenia. Journal of Abnormal

Psychology, 86(2), 103-126. 